\title{
Analysis on the Quality Assurance System of Doctoral Education
}

\section{Pengjun $\mathrm{Li}^{1, \text { a }}$}

${ }^{1}$ College of Life Science and Technology, Jinan University, Guangzhou, Guangdong, 510632

a email: pengjunsd@163.com

Keywords: Doctoral Education; Quality of Education; Security System

\begin{abstract}
At present, China's doctoral education has entered a new stage of development, how to build a scientific and effective quality education system of postgraduate education has become an urgent problem to be solved. Based on the basic foothold and training objectives of postgraduate education in China, this paper discusses the essence of doctoral education quality assurance system and summarizes the important factors that affect the quality of doctoral education, and gives some suggestions.
\end{abstract}

\section{Introduction}

Since 1999, China has the rapid expansion of the scale of graduate education. According to the "National Education Development Statistics Bulletin", China in 1998 to recruit graduate students 7.25 million, 19.88 million graduate students. In 2015, the number of enrollment graduate students was 64.51 million, with 119.14 million graduate students, including 32.67 million doctoral students and 158.47 million Master graduate students (see table).

Schedule: Number of Enrollment Students in 1998-2015 (Unit: 10,000) (Source: Ministry of Education National Education Development Statistics Bulletin)

\begin{tabular}{|c|c|c|c|c|c|c|}
\hline \multirow{2}{*}{$\begin{array}{c}\text { Num } \\
\text { Year }\end{array}$} & \multicolumn{2}{|c|}{ Number of enrollment } & \multicolumn{3}{c|}{ Number of students } \\
\cline { 2 - 7 } & Ph.D & Master & Total & Ph.D & Master & Total \\
\hline 1998 & 1.50 & 5.75 & 7.25 & 4.52 & 15.36 & 19.88 \\
\hline 1999 & 1.99 & 7.18 & 9.17 & 5.40 & 17.85 & 23.25 \\
\hline 2000 & 2.23 & 9.87 & 12.10 & 5.98 & 22.33 & 28.31 \\
\hline 2001 & 3.21 & 13.28 & 16.49 & 8.59 & 30.65 & 39.24 \\
\hline 2002 & 3.83 & 16.42 & 20.25 & 10.87 & 39.21 & 50.08 \\
\hline 2003 & 4.87 & 22.00 & 26.87 & 13.67 & 51.41 & 65.08 \\
\hline 2004 & 5.32 & 27.30 & 32.62 & 16.56 & 65.43 & 81.99 \\
\hline 2005 & 5.48 & 31.00 & 36.48 & 19.13 & 78.73 & 97.86 \\
\hline 2006 & 5.60 & 34.20 & 39.8 & 20.80 & 89.66 & 110.46 \\
\hline 2007 & 5.80 & 36.06 & 41.86 & 22.25 & 97.25 & 119.5 \\
\hline 2008 & 5.98 & 38.67 & 44.65 & 23.66 & 104.64 & 128.3 \\
\hline 2009 & 6.19 & 44.90 & 51.09 & 24.63 & 115.86 & 28.31 \\
\hline 2010 & 6.38 & 47.44 & 53.82 & 25.90 & 127.95 & 153.84 \\
\hline 2011 & 6.56 & 49.46 & 56.02 & 27.13 & 137.46 & 164.59 \\
\hline 2012 & 6.84 & 52.13 & 58.97 & 28.38 & 143.60 & 171.98 \\
\hline 2013 & 7.05 & 54.09 & 61.14 & 29.83 & 149.57 & 179.4 \\
\hline 2014 & 7.26 & 54.87 & 62.13 & 31.27 & 153.50 & 184.77 \\
\hline 2015 & 7.44 & 57.06 & 64.51 & 32.67 & 158.47 & 191.14 \\
\hline
\end{tabular}


From the table can be seen, by 2015, China's doctoral students enrollment and the number of students has reached 7.2 times in 1998, the number of Master graduate students enrollment and the number of students has reached 10.3 times in 1998. Graduate education has experienced a rapid expansion of the number, has entered the emphasis on improving the quality of the development stage. How to establish a reasonable and effective quality assurance system to ensure and improve the quality of training, has become an urgent need to address the important issues. As a high-level position in postgraduate education, doctoral education plays a leading role in the whole graduate training system, and its quality of education is the key factor to determine the quality of postgraduate education. This paper will summarize the relevant factors that affect the quality of doctoral education from the perspective of internal and external analysis and the training of doctoral students.

\section{The Establishment of Doctoral Education Quality Assurance System of the Foothold and Its Goals}

Talent training process is a gradual process of interaction. The basic conditions of students and subjective initiative can be regarded as internal factors. Mentor guidance, school education and other factors can be regarded as external factors. Scientific doctoral education process is to actively create and make full use of a variety of external factors, so that the effective role of internal factors, and guide the internal development process. The doctoral education quality assurance system is the essence of these external factors reasonable combination of effective system. The quality assurance system of doctoral education must be based on respecting and using the law of education, creating and applying favorable external factors, and realizing the harmony between inside and outside. ${ }^{[1]}$

According to the Regulations of the People's Republic of China, doctoral students should meet the following requirements: (1) To master a solid and broad basic theory and system in-depth expertise in the subject; (2) Have the ability to work independently in scientific research; (3) Make creative results in science or expertise. The above requirements fully reflect the respect for the law of personnel training. The requirements of the doctoral students can be summarized as "broad base, fine professional, good scientific research, innovation", which "wide base, fine professional" is the basic conditions, "good scientific research" is based on this ability, "Innovation" is in the foundation and ability at the same time to make the results, but also the ultimate goal of doctoral training.

\section{Pay Attention to Enrollment and to Absorb Quality Students}

Admission work is a doctoral graduate education in the internal conditions of the initial assessment and screening, but also the starting point of doctoral education work. The starting point of the level of a large extent affect the training process and results, therefore, must attach great importance to do the recruitment work, open channels to attract outstanding students.

Strict recruitment system, strengthen the screening function. Doctoral entrance examination, re-examination is the basic part of screening students, must strictly abide by the recruitment of work discipline and system to ensure that the relevant work fair and impartial, so that the screening of this part of the function is fully realized. In addition, the doctoral graduate entrance examination by the admissions unit independent issue, the units should pay more attention to the title and recruiting work, the use of unified examination and interview scientific examination of students, to further ensure that the recruitment function of scientific and effective.

Implementation of the successive postgraduate and doctoral programs of study, to retain high-quality students. Through the study of the master's degree, recommend excellent master's degree exemption for doctoral degree, but also effectively improve the quality of one of the ways. At the same time, this way can ensure that doctoral students in the master and doctor two stages of research to study the continuity of the content, so that the relevant work more systematic, in-depth, is conducive to high-level results of the output.

Explore the "application examination system", innovative recruitment model. To further 
improve the quality of our doctoral students enrollment, recruit more innovative ability to train top-notch talent, the current part of the domestic colleges and universities to retain the original open recruitment channels on the basis of some professional and quota pilot "application examination system", mainly through "Apply for assessment system" selection of outstanding doctoral students.

In order to further deepen the reform and development of doctoral students, we should explore and construct the system and mechanism that conforms to the training rules of doctoral students, so as to improve the quality of graduate students as the core, and select the modern science for the selection of modern science. Development requirements of the outstanding have innovative talents. Applicants must first complete the online registration within the specified time, and according to the college to submit to prove their ability to study, knowledge structure and scientific research potential of the application materials. After the first instance, to participate in the comprehensive assessment of the organization, by the assessment team on the applicant's overall quality, theoretical basis, academic interests and research potential, innovation ability and other aspects of comprehensive assessment, no longer need to participate in the school organization unified entrance examination. The Compared with the traditional enrollment, the "application examination system" will adhere to the "Just, Fair and Open" principle, focus on the candidates innovation and professional potential of the comprehensive in-depth examination, to achieve the optimization of students, to improve the effectiveness of selection, is One of the important measures of doctoral student enrollment reform.

Broaden the source of students, pay attention to the in-service students. Should pay attention to attract in-service students to apply for doctoral students, especially in the field of practice to achieve significant results in the master's degree and after graduation in colleges and universities, research institutes continue to engage in teaching and research work master's degree. Such students in scientific research ability, theory and practical ability, the results of the application of conversion capacity and other aspects compared to fresh students have more advantages.

Optimize the award system to attract high quality students. At present, the reform of the postgraduate training mechanism is underway. Colleges and universities should take this opportunity to optimize and perfect the doctoral student award system, improve the treatment of outstanding doctoral students, reduce the doctoral students to worry about, make it more investment to carry out research, But also conducive to attract excellent students apply.

Admissions are also a doctoral graduate education inside and outside the embodiment of the initial interaction. Whether a university can attract more high-quality students depends more on the comprehensive strength of the school, including school reputation, discipline level, tutor visibility and training environment. So to attract high-quality students can not one-sided emphasis on enrollment work, but also hard skills, pay attention to the overall strength of the school to enhance.

\section{Reform and Training Mode, Optimize the Training Process}

The process of training is the process of the gradual realization of the personnel training and the process of playing a role. It is also the most complicated process of internal and external interaction in doctoral education. The scientific training mode is helpful to give full play to the subjective and dynamic action of the external factors on the basis of respecting the law of personnel training, and to promote the mobilization of the doctoral students' subjective initiative and enhance the scientific research ability under the premise of consolidating the theoretical basis.

Respect the law of education and improve the training program. Training program provides a discipline under the professional training planning and direction, scientific and perfect training programs for high-quality personnel training is essential. The development of doctoral training program should first clear its training objectives, on this basis, fully respect the law of personnel training and develop a reasonable and effective training links and ways. The establishment of training programs should be avoided and combined with the specific characteristics of various disciplines by the academic committee to discuss the development.

According to the doctoral students to cultivate "wide foundation, fine professional, good scientific research, innovation" requirements, we should first pay attention to the doctoral students 
curriculum. The purpose of course teaching is to broaden and reinforce the foundation, to help doctoral students to build a broad theoretical basis and system of knowledge system. Only with this foundation, in order to achieve scientific research capacity and innovation ability to enhance, this is the process of personnel training in the progressive law of the inevitable requirement, otherwise "good scientific research, innovation" can only be castles in the air. On this basis, the development of training programs should also focus on scientific research and innovation ability of the exercise, requires doctoral students to participate in academic seminars, academic reports, and in the corresponding training links to meet the requirements of scientific research.

In the form of guidance, to take collective training, the mentor responsible for the form, is conducive to breaking the traditional "master with apprentice" model, broaden the academic perspective of students, is conducive to improving the efficiency of guidance and improve the quality of guidance.

Optimize the culture environment and create an academic atmosphere. A good academic atmosphere is conducive to stimulate academic enthusiasm, to mobilize academic enthusiasm. we should establish and improve the mechanism of academic activities, regular academic exchange activities, and strive to build a high level of academic exchange platform to encourage doctoral students to actively participate in them to create a good environment and atmosphere.

Improve the reward system to encourage scientific research and innovation. The reward system as an external factor has an important incentive for the cultivation of doctoral students. He should be combined with the ongoing training mechanism for graduate students to further improve the doctoral student award system. The establishment of ordinary scholarships, innovation funds, excellent doctoral dissertations funds and other funding content and targeted award projects, the introduction of a fair and reasonable evaluation of the summary system to encourage doctoral students engaged in scientific research and innovation.

Strict assessment criteria, the establishment of elimination mechanism. The survival of the fittest is a natural law, only the development of strict standards to ensure a certain elimination rate, in order to do doctoral education "strict" to ensure that the doctoral students to cultivate high quality. Therefore, the strict examination of the elimination mechanism is also an excellent part of the doctoral education quality assurance system. Aiming at the various aspects of doctoral education, this paper establishes a curriculum examination system with the subject examination as the main form, and publishes the scientific research examination system, which is the main form of the examination, and takes the examination and the double examination as the main form.

In the process of doctoral training, the pressure exemption mechanism is used to guide the incentive mechanism to provide the impetus. On the basis of the law of respect, the law is used to make full use of the influence of the external factors to mobilize the active action of the internal factors and keep the process control active Factors, in order to build a scientific and effective doctoral education quality assurance system framework. ${ }^{[2]}$

\section{Strengthen the Mentor Team Building and Improve the Level of Guidance}

Instructors as instructors and guides, the quality of doctoral training plays a key role. It can be said that the mentor's guidance is the most direct and influential external factor in the process of doctoral education. Therefore, it is necessary to strengthen the construction of the mentor team, improve the academic level and guide level of the instructor, and realize the guidance of the high level and scientific instructor.

Improve the mentor evaluation mechanism and activate the enthusiasm of mentor team. Most colleges and universities have established a doctoral tutor qualification selection system and this system has important positive significance for the construction of teachers. But at the same time, this system also needs further reform and improvement. At present, the "doctoral tutor" represents the doctoral graduate enrollment at the same time, has also become an honorary title, and almost universally become a life-long system of qualifications, in such a shade of some of the work. There is a burnout attitude, academic level and guidance level stagnation or even retrogression, doctoral tutor team construction need to introduce evaluation and competition mechanism. 
It is necessary to break the tenure system of doctoral tutor admissions qualification, should be developed to guide the enrollment to be met the assessment criteria, each year to conduct a review of the mentor, non-compliance must stop enrollment; To meet the relevant conditions of non-doctoral tutor admissions doctoral students; Doctoral candidates enrollment quota and tutor of scientific research projects, research funding, academic awards, published works and other indicators linked to support the development of excellent tutor. To introduce competition mechanism and elimination mechanism, so that teachers work hard to engage in scientific research work to enhance their academic level and guidance level. ${ }^{[3]}$

To promote the exchange of experience and improve the level of guidance. For the doctoral tutor, the academic level is only one aspect of its ability, with a high academic level does not mean that you can guide the excellent doctoral students. Doctoral tutor must master the scientific guidance, and constantly improve their own guidance level. Schools should regularly organize doctoral tutor experience exchange, invited senior instructors to do the report, for the mentor to build experience exchange platform. At the same time, the regular mentor informed the doctoral education of the new situation, so that the mentor in mastering the latest developments in doctoral education on the basis of timely adjustment of guidance methods, sum up guidance experience and achieve scientific guidance.

\section{Build Research Management Team and Improve Management and Service Quality}

Among the external factors that affect the quality of doctoral education, management services and mentor guidance are two key factors that are dynamic. The development of the methods, regulations, procedures, systems and systems of doctoral education is derived from the practice and thinking of the management department and put into practice under its operation. The work of the management department is to take full account of the need for internal development in doctoral education, to create and utilize favorable external factors (including the management itself) as much as possible, and to coordinate the development and scientific interaction. It can be seen that the level of management and service has an important influence on the quality of doctoral education. ${ }^{[4]}$

Strengthen the system construction, improve work efficiency. With the continuous development of graduate education, the management work is increasingly complicated, the importance of institutional construction highlights. Only by establishing a scientific and sound system and clarifying the processes and regulations of the work can we ensure that the work is carried out efficiently and orderly. This requires our managers to complete the specific work at the same time, must have standing on the specific affairs of the abstract thinking, summed up the ability to sum up the complex concrete work of the block, to develop a clear workflow and system to the program and the institutionalization of the work to ensure the efficiency and scientific.

Strengthen the study and improve their ability. After experiencing the rapid expansion of the scale, the current doctoral education and even the entire graduate education are faced with unprecedented challenges, new situations, new problems continue to emerge. How to grasp the situation, use and create favorable conditions, to avoid and solve the problem, guide the healthy development of graduate education, improve the quality of doctoral education, has become a need for systematic research in-depth issues.

The postgraduate education management personnel in the new situation can not be merely a business operator and must be a management researcher. It can no longer be limited to solving the problem, must also be good at a rainy day. Managers must continue to improve their level and quality, grasp the development of graduate education situation, in the work to carry out learning and research.

To build a research management team to serve the quality of education. The construction of the research management team is not only the need to ensure the quality of doctoral education, but also the need to build high-level research universities. Therefore, colleges and universities and graduate management departments should attach great importance to the construction of the management team to encourage and require managers to engage in management research, writing management papers; regularly carry out management seminars, exchange experience; support 
management in the field of education management. To create a research atmosphere, to create a research-based management team, comprehensively enhance the management level and quality of service for the improvement of the quality of education to provide a solid guarantee.

\section{Acknowledgment}

Fund Project: Guangdong Province degree and graduate education reform research project" Graduate student training research based on the sharing of resources "(No. 2014JGXM-MS06), Guangdong Province Department of education Seedling project" A research of graduate education development quality system "(No. WYM10078).

\section{References}

[1] Huang Baoying, Xu Weiqing, Zhang Yan, Hao Tongliang. Accelerate the establishment and improvement of China's degree and postgraduate education quality assurance and supervision system [J]. Degree and Postgraduate Education, 2014 (3): 1-9.

[2] Lin Mengquan, Gong Zhenzhi. Study on the new trend of evaluation of degree and postgraduate education in China [J]. China Higher Education, 2007 (2): 36-38.

[3] Zhou Wenhui, Li Minglei. Study on quality assurance mechanism of postgraduate training based on university survey [J]. Educational Research, 2013 (3): 59-65.

[4] Zhang Yingwei, Lu Xuewen. Reform and innovation of postgraduate training model in China [J].China Higher Education, 2016 (20): 45-46. 